\title{
IGF-I and IGF-Binding Proteins in Articular Exudates of Children with Post-Traumatic Knee Damage and Juvenile Idiopathic Arthritis
}

\author{
Tomasz Guszczyn ${ }^{a}$ Justyna Rzeczycka ${ }^{b}$ Janusz Popko ${ }^{a}$ \\ a Department of Paediatric Orthopaedics and Traumatology, and ${ }^{\mathrm{b}}$ Department of Medical Biochemistry, \\ Medical University of Białystok, Białystok, Poland
}

\section{Key Words}

Gelatinases · Insulin-like growth factor-I · IGF-binding protein · Juvenile idiopathic arthritis - Post-traumatic damage $\cdot$ Synovial fluid

\begin{abstract}
Objective: IGF-I stimulates multiple functions of connective tissue cells and its activity is modulated by IGF-binding proteins (BPs). Some metalloproteinases are expected to modify IGF-I activity by digestion of IGF-BPs. It was decided to evaluate the concentration of IGF-I, IGF-BPs and the activity of gelatinases $A$ and $B$ in knee exudates of children with posttraumatic damage (PTD) and children with juvenile idiopathic arthritis (JIA) in comparison with those in the sera of the same patients. Methods: ELISA (for IGF-I assay), polyacrylamine gel electrophoresis following Western immunoblotting (for IGF-I and IGF-BPs expression), and zymography (for gelatinase detection) were used. Results: The knee exudates, especially those taken from patients with JIA, contained large amounts of IGF-I. The exudates of PTD and JIA patients contained some forms of IGF-BP-1 of molecular weight lower than those occurring in serum. Low expression BP-3 and high activity of gelatinase B were detected in the JIA exudates. Conclusions: The high gelatinase activities in exudates imply joint tissue damage. The cellular response to damage of this kind is an increase in IGF-I production, which stimulates repair processes. High proteolytic activities of ge-
\end{abstract}

latinase B in JIA patients may lower the amount of BP-3, possibly causing a relative decrease of IGF-I concentration and impairing the reparation processes stimulated by IGF-I.

Copyright $\odot 2009$ S. Karger AG, Basel

\section{Introduction}

The extracellular matrix of normal articular cartilage is composed mainly of collagens, proteoglycans, link proteins and hyaluronic acid. Cartilage integrity is maintained by strict regulation of the balance between degradation and synthesis of these components. To some extent, most of the factors responsible for articular tissue homoeostasis act on articular chondrocytes via synovial fluid [1-3].

The inflammatory processes in articular tissues are accompanied by degradation of synovial compounds by hydrolytic enzymes, enhanced by pro-inflammatory cytokines and reparation response stimulated by peptide growth factors, which enhance both the cell divisions and biosynthesis of extracellular matrix components $[4,5]$.

While the pro-inflammatory cytokines appear to be responsible for degradation of the major cartilage macromolecules and inhibition of their synthesis, the peptide growth factors have been postulated to improve cartilage anabolism [6-9].

\section{KARGER}

Fax +41613061234

E-Mail karger@karger.ch

www.karger.com (c) 2009 S. Karger AG, Basel

1015-2008/09/0765-0260\$26.00/0

Accessible online at:

www.karger.com/pat
Tomasz Guszczyn

Department of Pediatric Orthopedics and Traumatology

Waszyngtona $17 \mathrm{Str}$.

PL-15-274 Białystok (Poland)

Tel./Fax +48 8574508 95, E-Mail tombial@mp.pl 
IGF-I is an important metabolic and mitogenic factor involved in cell growth and differentiation, and is known as a stimulator of collagen and sulphated glycosaminoglycans [10-12]. IGF-I in plasma and tissues is complexed to binding proteins (BPs), which are important regulators of its biological activity.

At least 6 different high-affinity BPs have been identified in humans and other species [13]. Furthermore, a family of 4 low-affinity BPs have been discovered. Under normal conditions, most IGF-I circulates in a form that is bound to a high-molecular-weight complex $(150 \mathrm{kDa})$, containing BP-3 as an active constituent $[14,15]$. It has been suggested that such a complex prolongs the half-life of IGF-I and increases cell responsiveness to IGF-I stimulation. Some BPs (BP-1, BP-2) are known inhibitors of functions that are dependent on IGF-I [7].

Another factor that may be important in regulating the availability of IGF-I to its receptor is a limited BP-3 cleavage product. Proteolysis of BP-3 $(46 \mathrm{kDa})$ produces a $30-\mathrm{kDa}$ fragment that can still bind IGF-I, but with reduced affinity $[13,16]$.

It is known that the peptide growth factors, especially IGF-I and IGF-binding proteins (IGF-BPs), play an important role in regulation of cell division and maintaining equilibrium between synthesis and degradation of extracellular matrix components [13]. We expect that IGF-I, its bioavailability, as well as BPs and their cleavage products, may contribute to remodelling extracellular matrix in articular tissues. They may also be involved in reparation of inflammation-induced damage of both synovial tissue and articular cartilage $[8,9]$.

Therefore, the characterization of IGF-I, IGF-BPs and IGF-BP proteases in synovial fluid is important for understanding the modulation of synovial tissue and articular cartilage metabolism in inflammatory processes affecting the knee joints.

We decided to measure the concentrations of IGF-I, IGF-BP-1 and IGF-BP-3 and evaluate gelatinolytic activity in both articular exudates and serum of patients with juvenile idiopathic arthritis (JIA) compared with those of patients with post-trauma articular fluid.

\section{Patients and Methods}

The protocols used in this study were accepted by the committee for ethics and supervision on human and animal research of the Medical University of Białystok and it was conducted in accordance with the Declaration of Helsinki.

\section{Patients}

Studies were performed on 12 patients ( 7 boys and 5 girls, aged 8-13 years), who experienced post-traumatic damage (PTD) of the knee joints, and on 12 patients ( 4 boys and 8 girls, aged 9-12 years), with oligoarticular JIA.

The studies were undertaken during arthrocentesis for diagnostic or therapeutic purposes at the early stages of their respective diseases, shortly after the children's first admission to hospital.

JIA was diagnosed according to criteria recommended by the International League of Associations for Rheumatology. Furthermore, the patients with JIA received methotrexate and/or sulphasalasine, although none of them received intra-articular injection of corticosteroids. All patients were, however, treated with non-steroidal anti-inflammatory drugs.

\section{Serum and Articular Exudates}

Blood was collected into a glass test tube and allowed to clot in room temperature. The retracted clot was removed by centrifugation, and the serum collected and stored at $-70^{\circ} \mathrm{C}$ until required for further use.

Samples of exudates were taken from the knee joints of both groups of patients during the arthrocentesis performed for diagnostic or therapeutic purposes. The samples of exudates were centrifuged, with the supernatants collected and stored at $-70^{\circ} \mathrm{C}$ prior to further use.

\section{SDS-PAGE}

This was performed according to the Laemmli method [17], using molecular weight standards (Bio-Rad).

\section{Gelatin Zymography}

This was performed by the method described by Unemori and Werb [18]. The sera and exudates were mixed with a Laemmli sample buffer [17] containing 3.0\% SDS (without reducing agent). Equal amounts $(10 \mu \mathrm{g})$ of protein were electrophoresed under no reducing conditions on $7.5 \%$ polyacrylamide gel containing gelatin in a concentration of $1 \mathrm{mg} / \mathrm{ml}$.

After electrophoresis, the gels were submitted to extraction of SDS with $0.25 \%$ Triton $\mathrm{X}-100(2 \times 15 \mathrm{~min})$ at room temperature and then transferred into $0.05 \mathrm{M}$ Tris/ $\mathrm{HCl}, \mathrm{pH} 7.5$, containing 10 $\mathrm{mmol} / 1 \mathrm{CaCl}_{2}, 1 \mu \mathrm{mol} / 1 \mathrm{ZnCl}_{2}, 0.02 \% \mathrm{NaN}_{3}$ and $1 \%$ Triton X-100. The mixture was incubated for $16 \mathrm{~h}$ at $37^{\circ} \mathrm{C}$.

After incubation, the gels were stained with $1 \%$ Coomassie Brilliant Blue R-250 for $14 \mathrm{~h}$ and distained with $10 \%$ acetic acid plus $25 \%$ isopropanol. The position of gelatin-degrading enzymes present in the sera and exudates became visible as clear zones on a blue background.

\section{Casein Zymography}

In order to detect MMP-7, casein zymography was performed by the method described by Zeng et al. [19] using NOVEX 4-16\% zymogram blue casein gels (Invitrogen, Carlsbad, Calif., USA).

\section{Western Blot Analysis}

After SDS-PAGE, the gels were allowed to equilibrate for $5 \mathrm{~min}$ in $25 \mathrm{mmol} / \mathrm{l}$ Tris, $0.2 \mathrm{~mol} / \mathrm{l}$ glycine in $20 \%$ (v/v) methanol. The protein was transferred to $0.2-\mu \mathrm{m}$ pore-sized nitrocellulose membranes at $100 \mathrm{~mA}$ for $1 \mathrm{~h}$ using an LKB 2117 Multiphor II electrophoresis unit (Amersham Pharmacia Biotech, Uppsala, Sweden). 
Fig. 1. a Concentrations of IGF-I in knee exudates (white bars) and in serum (black bars). $\mathbf{b}$ Exudate/serum ratio of IGF-I concentrations in those patients $(\mathrm{p}<0.05)$.
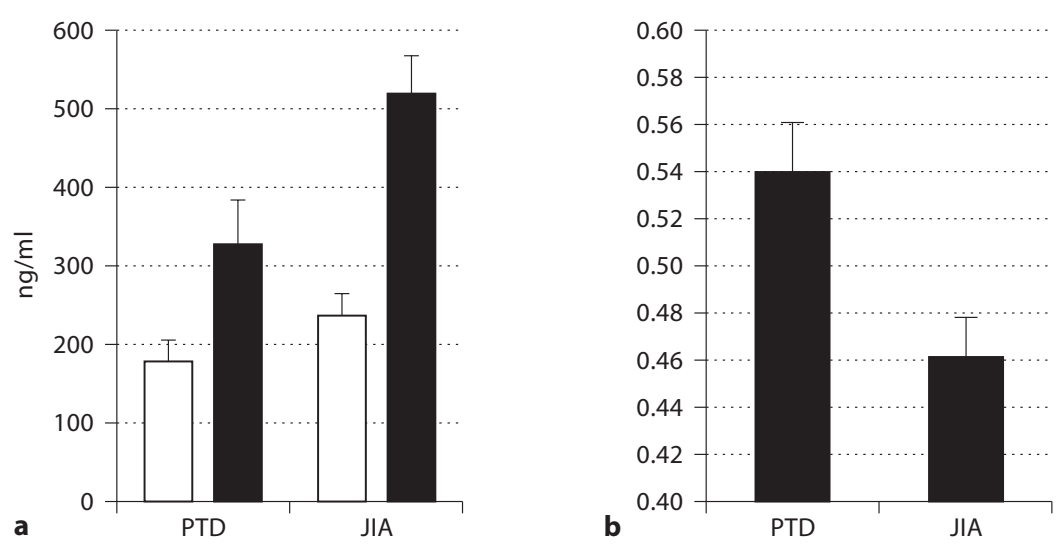

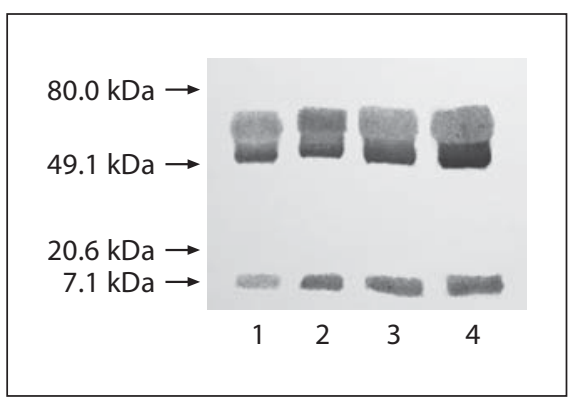

Fig. 2. Western immunoblot analysis for IGF-I. Lanes: $1=$ Exudates of PTD patients; 2 = exudates of JIA patients; 3 = sera of PTD patients, and $4=$ sera of JIA patients. The same amount of extract protein $(10 \mu \mathrm{g})$ was run on each lane. Western immunoblot analysis was performed on pooled exudates or sera of 12 PTD and 12 JIA patients.

The membranes were incubated with proper monoclonal antibodies: anti-IGF-I, anti-IGF-BP-1 or anti-IGF-BP-3 (Sigma-Aldrich, St. Louis, Mo., USA) diluted 1:500 in 5\% dried milk in TBST $(20 \mathrm{mmol} / \mathrm{l}$ Tris-HCl buffer, $\mathrm{pH}$ 7.4, containing $150 \mathrm{mmol} / \mathrm{l}$ $\mathrm{NaCl}$ and $0.05 \%$ Tween 20 ) for $1 \mathrm{~h}$, followed by alkaline phosphatase-conjugated second antibodies against mouse Fc IgG, added at a concentration 1:2,000 in TBS-T.

Incubation was continued for $30 \mathrm{~min}$ with slow shaking. Then, in both cases, nitrocellulose was washed with TBS-T ( 5 times for $5 \mathrm{~min}$ ) and submitted to the action of Sigma Fast BCIP/NBT reagent.

\section{IGF-I Assay}

The presence of IGF-I in the examined material was detected by Western blot analysis as described in the previous paragraph, and its quantitative assay was performed with a human IGF-I quantikine ELISA kit (provided by R\&D Systems) according to the producer's instructions.
Detection of IGF-BP-1 and IGF-BP-3

IGF-BP-1 and IGF-BP-3 were detected by Western immunoblot analysis as described in the previous paragraph.

\section{Statistical Analysis}

In all experiments, the mean values for 12 assays \pm standard deviations were calculated. The results were submitted for statistical analysis with the use of Student's t test, accepting $\mathrm{p}<0.05$ as significant.

\section{Results}

Figure 1 demonstrates the concentrations of IGF-I measured by ELISA. Figure 1a shows that the examined exudates contained significant amounts of IGF-I. The material taken from PTD patients contained IGF-I in concentrations of about $178 \mathrm{ng} / \mathrm{ml}$, whereas the material taken from JIA patients contained distinctly more IGF-I, about $237 \mathrm{ng} / \mathrm{ml}$.

A similar situation was observed in the sera of the examined patients. Much more IGF-I was found in JIA patients (about $518 \mathrm{ng} / \mathrm{ml}$ ) compared with the PTD patients (about $327 \mathrm{ng} / \mathrm{ml}$ ). It is of special interest that both the sera and exudates of the JIA patients contained distinctly more IGF-I than the sera and exudates of the PTD patients. But the ratio of IGF-I concentrations (fig. 1b) in exudates and sera is distinctly lower in JIA patients compared to those with PTD.

It appears from figure 2 that IGF-I contained in the exudates and sera of both PTD and JIA patients divided into 2 main fractions during electrophoresis. One of them (in the less intensive bands) of molecular weight around 
Fig. 3. Western immunoblot analysis for IGF-BP-1 in non-reducing (a) and reducing (b) conditions. Lanes: 1 = Exudates of PTD patients; 2 = exudates of JIA patients; $3=$ sera of PTD patients, and $4=$ sera of JIA patients. The same amount of extract protein $(10 \mu \mathrm{g})$ was run on each lane. Western immunoblot analysis was performed on pooled exudates or sera of 12 PTD and 12 JIA patients.

Fig. 4. Western immunoblot analysis for IGF-BP-3 in non-reducing (a) and reducing (b) conditions. Lanes: 1 = Exudates of PTD patients; 2 = exudates of JIA patients; $3=$ sera of PTD patients, and $4=$ sera of JIA patients. The same amount of extract protein $(10 \mu \mathrm{g})$ was run on each lane. Western immunoblot analysis was performed on pooled exudates or sera of 12 PTD and 12 JIA patients.
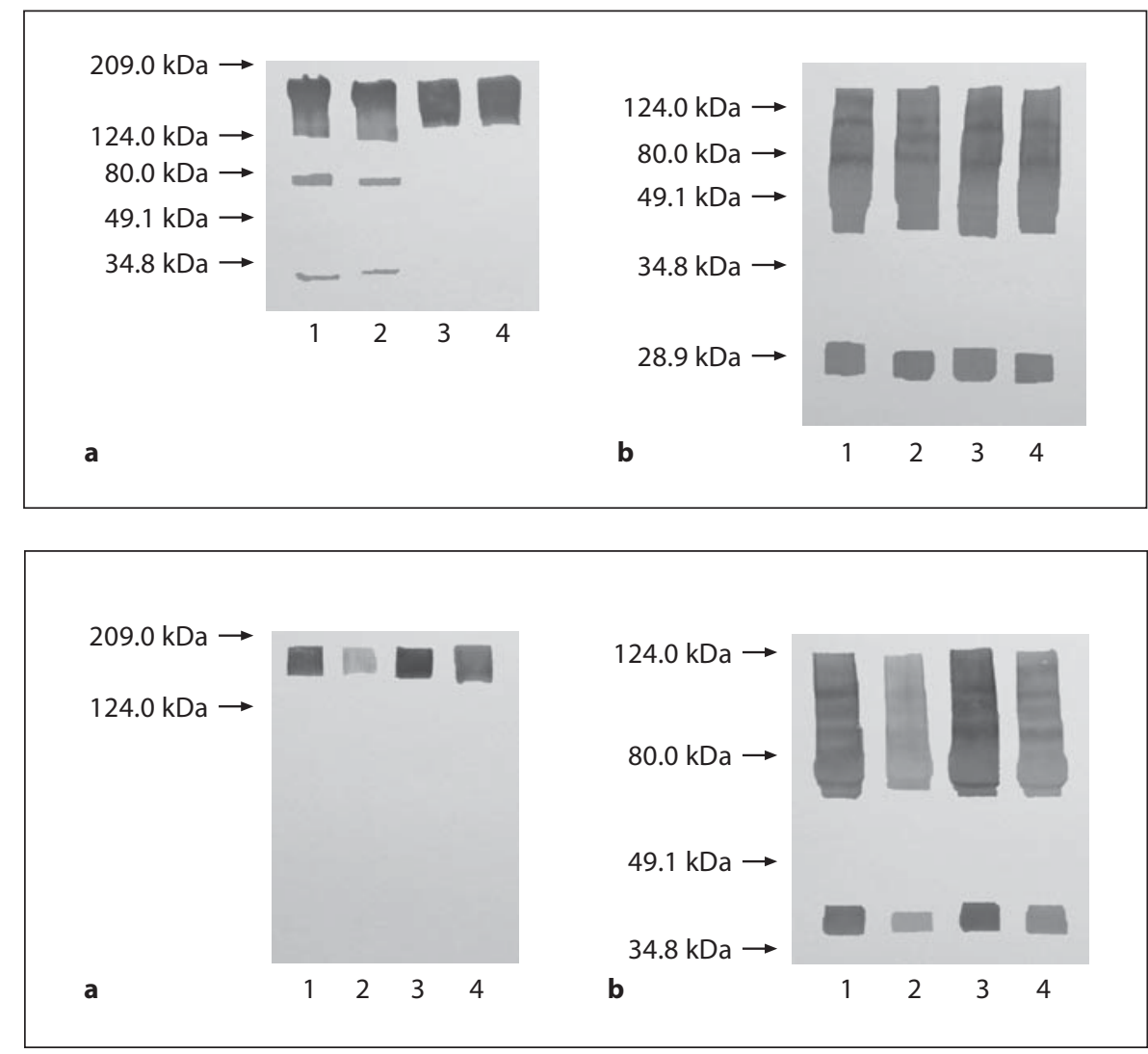

$7.5 \mathrm{kDa}$, corresponds to free IGF-I. The other fraction (wide and distinctly more intensive bands) of molecular weight about 55-40 kDa, corresponds to complexes of IGF-I with some binding proteins.

It appears from the immunoblot presented in figure $3 \mathrm{a}$ (lanes 3 and 4) that the sera of both groups of patients contain a BP which interacts with anti-BP-1, and which migrates during electrophoresis in non-reducing conditions in a form of 1 wide band of molecular weight of about $150 \mathrm{kDa}$. In contrast, the exudates of PDT and JIA patients contain a heterogeneous group of BPs that interact with anti-BP-1. The main ones seem to be identical to those present in the sera, but 2 other bands of molecular weight of about 75 and $29-30 \mathrm{kDa}$ (lanes 1 and 2) are visible.

It appears from figure $3 \mathrm{~b}$ that the action of $\beta$-mercaptoethanol results in a dissociation of high-molecularweight complex (reacting with anti-BP-1) into components of lower molecular weight, the main ones demonstrating molecular weight of about $29 \mathrm{kDa}$. This corresponds to a free form of BP-1. Furthermore, some bands of higher molecular weight (about 80 and $100 \mathrm{kDa}$ ) were visible. Similar electrophoretic patterns were achieved both in the sera and the exudates.

Figure 4a shows that both the sera and exudates from PDT and JIA patients contain a homogenous, high-molecular-weight complex (about $150 \mathrm{kDa}$ ) that interacts with anti-BP-3 antibody (lanes 1-4). Notably, the intensity of $150-\mathrm{kDa}$ bands was weaker in the exudates and sera of JIA patients (lanes 2 and 4) than in those of PTD patients (lanes 1 and 3 ).

Under the action of $\beta$-mercaptoethanol the homogenous $150-\mathrm{kDa}$ materials dissociated into products of lower molecular weight, mainly (about $40 \mathrm{kDa}$ ) corresponding to a free form of BP-3 (fig. 4b). As in the case of nonreduced $(150 \mathrm{kDa})$ material, the intensity of bands corresponding to reduction products was weaker in JIA patients (lanes 2 and 4) compared to those in PTD patients (lanes 1 and 3).

From figure 5, it appears that both the sera and the exudates contain gelatinases. Far more intensive gelatinolysis is visible in exudates (lanes 1 and 2) than in the samples containing sera (lanes 3 and 4). Both gelatinase A (MMP-2) and gelatinase B (MMP-9) were found. Con- 


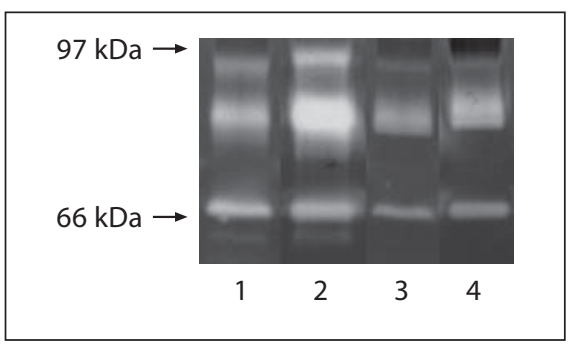

Fig. 5. Gelatinolytic activities of exudates and sera of PTD and JIA patients. Lanes: 1 = exudates of PTD patients; 2 = exudates of JIA patients; 3 = sera of PTD patients, and $4=$ sera of JIA patients. The same amount of extract protein $(10 \mu \mathrm{g})$ was run each lane. Gelatinolytic activities were performed on pooled exudates or sera of 12 PTD and 12 JIA patients.

versely, the casein zymography did not detect MMP-7 (not shown in any figure).

Gelatinase A in its active form (about $62 \mathrm{kDa}$ ) was detected in trace amounts in exudates only (lanes 1 and 2). The sera (lanes 3 and 4) did not, however, contain active gelatinase A. The exudates, especially those from JIA patients (lane 2), contained large amounts of the zymogen form of this enzyme $(72 \mathrm{kDa})$.

Contrasted with gelatinase $\mathrm{A}$, gelatinase $\mathrm{B}$ was detected in the sera and in the exudates both in active $(82 \mathrm{kDa})$ and latent $(92 \mathrm{kDa})$ forms. Interestingly, the exudates of JIA patients (lane 2) demonstrated very high amounts of both latent and active forms of this enzyme.

\section{Discussion}

Equilibrium between the synthesis and degradation of cartilage matrix is required to maintain the integrity of the tissue. Multiple pathological conditions, including various forms of arthritis, cause distortion of that balance. Although the pathogenesis of these diseases is different, the final pathway for joint destruction appears to be the same. The disruption of homoeostasis occurs between the synthesis and the degradation favouring the catabolic process. Consequently, this leads to loss of cartilage.

We believe that increased activity of proteolytic enzymes (metalloproteinases) is responsible for the intensified catabolism, whereas a lack of anabolic action of growth factors would be responsible, at least in part, for the decreased reconstruction of extracellular matrix.

We found that the knee exudates, especially those taken from patients with JIA, contained large amounts of
IGF-I. No data concerning IGF-I concentration in children's synovial fluid have been published. Matsumoto et al. [20] reported that synovial fluid of adult subjects contains about 19 ng of IGF-I per ml, which corresponds to about $10 \%$ of serum concentration. The amounts of IGFI in the exudates were distinctly higher (about $177 \mathrm{ng} / \mathrm{ml}$ in the PTD group and $236 \mathrm{ng} / \mathrm{ml}$ in the JIA group), which correspond to 54 and $46 \%$ of serum values in PTD and JIA patients, respectively.

The IGF-I concentration in the sera of PTD patients is comparable to values reported for the age group under consideration [21], whereas in JIA patients this value was distinctly higher.

According to some authors [22-24], the JIA patients demonstrated lower IGF-I level in their sera. However, there is no disagreement between our IGF assays and those reported by other authors.

As described in 'Materials and Methods', our studies were conducted for diagnostic or therapeutic purposes on patients with oligoarticular JIA during arthrocentesis at the early stages of their conditions, shortly after their first admission to hospital. None of the children received an intra-articular injection of corticosteroids.

Compared to our study, those reported by other authors [22-24] were performed on patients suffering from polyarticular and systematic JIA at advanced stages of the diseases, some lasting up to 12 years [24]. Before the material for IGF-I assay was taken, most of the patients were treated with corticosteroids [22-24], which are known to be inhibitors of IGF-I biosynthesis, at least in some cells [25].

Significantly, the ratio of IGF-I concentrations in exudates and sera is distinctly higher in PTD patients compared to those with JIA. This allows us to suggest that trauma induces a local increase in IGF-I production by damaged tissues and its secretion into the articular exudates. Higher amounts of IGF-I may promote the repair process in an injured knee joint by stimulation of cell divisions and anabolic processes.

In the case of both exudates and sera, only small parts (a few percent) of IGF-I were found in a free form. The rest was complexed with IGF-BPs.

Such a phenomenon may be extremely important for IGF-I stability, since we know that the half-life of free IGF-I is $10 \mathrm{~min}$, whereas that of IGF-I-BP-3 is 10 to $15 \mathrm{~h}$ [26].

The main part of this factor was bound to high-molecular-weight complexes that interact with anti-IGF-BP antibodies. In our study, both IGF-BP-1 and IGF-BP-3 were found. The bands corresponding to BP-3 in JIA ex- 
udates were weaker in comparison to those observed in PTD exudates. Knowing that the molecular weight of BP1 equals about $28 \mathrm{kDa}$ [27], it is interesting that both PTD and JIA sera do not contain such material. High-molecular-weight complexes that react with anti-BP-1 antibody were discovered, the majority dissociating under the action of reducing agents with a release of products corresponding to free BP-1.

Compared with sera, both PTD and JIA exudates contain slight amounts of free BP-1 and some products of higher molecular weight, which may be complexes of BP1 with other proteins. Most of them dissociate under the action of reducing agent with an intensive release of free BP-1.

The articular exudates demonstrated the presence of gelatinases A and B. Significantly, exudates taken from JIA patients demonstrated a large amount of both active and latent forms of gelatinase $\mathrm{B}$. The high activity of this enzyme co-exists with a decrease in amounts of BP-3 in the JIA exudates. Although several metalloproteinases, mainly MMP-7, digest IGF-binding proteins, including BP-3 [13, 20, 28, 29], both gelatin and casein zymography did not detect MMP-7 in our material. In a comprehensive review by Wilson and Matrisian [30], gelatin is also mentioned as a substrate for MMP-7, but gelatin zymography did not detect MMP-7 in our material. It is, therefore, very likely that the non-specific proteolytic action of gelatinase B results in a cleavage of BP-3 and a decrease of its content in JIA exudates.
BP-3 is acknowledged as a main factor that protects IGF-I against proteolytic degradation. The high activity of gelatinase B in the JIA exudates may enhance the BP-3 proteolysis, promoting IGF-I degradation in this fluid $[31,32]$. However, the increase in IGF-I concentration both in the sera and articular exudates of JIA patients may result from enhanced biosynthesis, decreased degradation of this growth factor, or from a combination of both phenomena.

Both the sera and exudates of these patients contained high amounts of IGF-I, despite the concentration of antiproteolytic BP-3 being low. As such, the most probable mechanism for the increase in IGF-content in their biological fluids is enhancement of IGF-I biosynthesis in articular tissues affected by the inflammatory process. Furthermore, BP-3 is not the only factor which inhibits IGFI degradation.

The high gelatinase activity in exudates evokes damage to cartilage and synovial tissues [33]. The cells respond to the damage with increased bioavailability of IGF-I that stimulates repair processes [34]. The high activity of gelatinase B in articular exudates of JIA patients may degrade the BP-3, possibly causing a relative decrease of IGF-I concentration in the fluid, and may also impair the reparation processes stimulated by IGF-I.

\section{Acknowledgement}

Linguistic help of Mr. Mark Nicholson is greatly appreciated.

\section{References}

$>1$ Buckwalter JA, Mankin HJ: Articular cartilage: tissue design and chondrocyte-matrix interactions. Instr Course Lect 1998;47:477486.

-2 Poole AR, Rizkalla G, Ionescu M, Reiner A, Brooks E, Rorabeck C, Bourne R, Bogoch E: Osteoarthritis in the human knee: a dynamic process of cartilage matrix degradation, synthesis and reorganization. Agents Actions Suppl 1993;39:3-13.

-3 Pascual E, Jovaní V: Synovial fluid analysis Best Pract Res Clin Rheumatol 2005;19:371386.

-4 Fernandes JC, Martel-Pelletier J, Pelletier JP: The role of cytokines in osteoarthritis pathophysiology. Biorheology 2002;39:237-246.

$>5$ Pelletier JP, DiBattista JA, Roughley P, McCollum R, Martel-Pelletier J: Cytokines and inflammation in cartilage degradation. Rheum Dis Clin North Am 1993;19:545568 .
6 Borzì RM, Mazzetti I, Marcu KB, Facchini A: Chemokines in cartilage degradation. Clin Orthop Relat Res 2004;427(suppl):S53-S61.

$>7$ Trippel SB: Growth factor actions on articular cartilage. J Rheumatol Suppl 1995;43: 129-132.

8 Schmidt MB, Chen EH, Lynch SE: A review of the effects of insulin-like growth factor and platelet derived growth factor on in vivo cartilage healing and repair. Osteoarthritis Cartilage 2006;14:403-412.

$\checkmark 9$ Verschure PJ, Van Noorden CJ, Van Marle J, Van den Berg WB: Articular cartilage destruction in experimental inflammatory arthritis: insulin-like growth factor-1 regulation of proteoglycan metabolism in chondrocytes. Histochem J 1996;28:835-857.

10 Laron Z: Insulin-like growth factor-I (IGFI): safety and efficacy. Pediatr Endocrinol Rev 2004;2(suppl 1):78-85.
11 Guenther HL, Guenther HE, Froesch ER, Fleisch H: Effect of insulin-like growth factor on collagen and glycosaminoglycan synthesis by rabbit articular chondrocytes in culture. Experientia 1982;38:979-981.

-12 McQuillan DJ, Handley CJ, Campbell MA, Bolis S, Milway VE, Herington AC: Stimulation of proteoglycan biosynthesis by serum and insulin-like growth factor-I in cultured bovine articular cartilage. Biochem J 1986; 240:423-430.

13 Lejbach A, Muzes G, Feher J: The insulinlike growth factor system: IGFs, IGF-binding proteins and IGFBP-proteases. Acta Physiol Hung 2005;92:97-107.

14 Collett-Solberg PF, Cohen P: Genetics, chemistry, and function of the IGF/IGFBP system. Endocrine 2000;12:121-136.

15 Martin JL, Baxter RC: Insulin-like growth factor binding protein-3: biochemistry and physiology. Growth Regul 1992;2:88-99. 
16 Clemmons DR, Jones JI, Busby WH, Wright G: Role of insulin-like growth factor binding proteins in modifying IGF actions. Ann NY Acad Sci 1993;692:10-21.

17 Laemmli UK: Cleavage of structural proteins during the assembly of the head of bacteriophage T4. Nature (London) 1970;227: 680-685.

18 Unemori EN, Werb Z: Reorganization of polymerized actin: a possible trigger for induction of procollagenase in fibroblasts cultured in and on collagen gels. J Cell Biol 1986;103: 1021-1031.

19 Zeng ZS, Shu WP, Cohen AM, Guillem JG: Matrix metalloproteinase-7 expression in colorectal cancer liver metastases: evidence for involvement of MMP-7 activation in human cancer metastases. Clin Cancer Res 2002;8:144-148.

-20 Matsumoto T, Gargosky SE, Iwasaki K, Rosenfeld RG: Identification and characterization of insulin-like growth factors (IGFs), IGF-binding proteins (IGFBPs), and IGFBP proteases in human synovial fluid. J Clin Endocrinol Metab 1996;81:150-155.

-21 Löfqvist C, Andersson E, Gelander L, Rosberg S, Blum WF, Albertsson Wikland K: Reference values for IGF-I throughout childhood and adolescence: a model that accounts simultaneously for the effect of gender, age and puberty. J Clin Endocrinol Metab 2001; 86:5870-5876.
22 De Benedetti F, Meazza C, Oliveri M, Pignatti P, Vivarelli M, Alonzi T, Fattori E, Garrone S, Barreca A, Martini A: Effect of IL-6 on IGF binding protein-3: a study in IL-6 transgenic mice and in patients with systemic juvenile idiopathic arthritis. Endocrinology 2001;142:4818-4826.

23 Davies K, Stiehm ER, Woo P, Murray KJ: Juvenile idiopathic polyarticular arthritis and IgA deficiency in the 22q11 deletion syndrome. J Rheumatol 2001;28:2326-2334.

24 Wong SC, MacRae VE, Gracie JA, McInnes IB, Galea P, Gardner-Medwin J, Ahmed SF: Inflammatory cytokines in juvenile idiopathic arthritis: effects on physical growth and the insulin-like-growth factor axis. Growth Horm IGF Res 2008;18:369-378.

25 Swolin D, Brantsing C, Matejka G, Ohlsson C: Cortisol decreases IGF-I mRNA levels in human osteoblast-like cells. J Endocrinol 1996;149:397-403.

26 Guler HP, Zapf J, Schmid C, Froesch ER: Insulin-like growth factors I and II in healthy man. Estimations of half-lives and production rates. Acta Endocrinol (Copenh) 1989; 121:753-758.

27 Frost RA, Tseng L: Insulin-like growth factor-binding protein-1 is phosphorylated by cultured human endometrial stromal cells and multiple protein kinases in vitro. J Biol Chem 1991;266:18082-18088.

28 Fowlkes JL, Thrailkill KM, Serra DM, Suzuki K, Nagase H: Matrix metalloproteinases as insulin-like growth factor binding protein-degrading proteinases. Prog Growth Factor Res 1995;6:255-263.
29 Fowlkes JL, Enghild JJ, Suzuki K, Nagase H: Matrix metalloproteinases degrade insulinlike growth factor-binding protein-3 in dermal fibroblast cultures. J Biol Chem 1994; 269:25742-25746.

30 Wilson CL, Matrisian LM: Matrilysin: An epithelial matrix metalloproteinase with potentially novel functions. Int J Biochem Cell Biol 1996;28:123-136.

31 Mañes S, Llorente M, Lacalle RA, GómezMoutón C, Kremer L, Mira E, Martínez AC: The matrix metalloproteinase- 9 regulates the insulin-like growth factor-triggered autocrine response in DU-145 carcinoma cells. J Biol Chem 1999;274:6935-6945.

-32 Belizon A, Kirman I, Balik E, Karten M, Jain S, Whelan RL: Major surgical trauma induces proteolysis of insulin-like growth factor binding protein-3 in transgenic mice and is associated with a rapid increase in circulating levels of matrix metalloproteinase-9. Surg Endosc 2007;21:653-658.

33 Itoh T, Matsuda H, Tanioka M, Kuwabara K, Itohara S, Suzuki R: The role of matrix metalloproteinase-2 and matrix metalloproteinase- 9 in antibody-induced arthritis. J Immunol 2002;169:2643-2647.

34 Martin JA, Scherb MB, Lembke LA, Buckwalter JA: Damage control mechanisms in articular cartilage: the role of the insulinlike growth factor I axis. Iowa Orthop J 2000; 20:1-10. 